\title{
A Etnomatemática na formação inicial dos futuros professores de Matemática: revelando olhares e marcas
}

\author{
Gisele Américo Soares \\ Maria Cecilia Fantinato
}

\begin{abstract}
Resumo: Esta investigação teve como objetivo analisar as marcas deixadas pela Etnomatemática na Licenciatura de Matemática. Este estudo apoiou-se nos referenciais teóricos da Etnomatemática e da Formação de Professores. Identificamos por meio do e-MEC cinco cursos com disciplinas cujo nome apresentava a palavra Etnomatemática. Realizamos entrevista com os professores de tais disciplinas e aplicamos questionário eletrônico aos estudantes. Os resultados da pesquisa apontaram algumas contribuições da Etnomatemática, no que tange a quebra de paradigmas em relação a universalidade da Matemática e suas implicações na perspectiva de ensino e aprendizagem dos licenciandos. As marcas identificadas foram: a necessidade da valorização do contexto social, econômico e cultural dos futuros estudantes, o reconhecimento da Matemática como construção humana, a abertura para o diálogo e a humanização do processo educativo.
\end{abstract}

Palavras-chave: Etnomatemática. Formação inicial de professores de Matemática. Currículo.

Gisele Américo Soares

Doutora em Educação pela Universidade Federal Fluminense (UFF), campus Gragoatá. Professora da Universidade

Estácio de Sá, AEDB e Rede Estadual de

Ensino do Rio de Janeiro. Resende, RJ,

Brasil

Dttps://orcid.org/0000-0003-1406

1835

\ giseleamerico@hotmail.com

Maria Cecilia Fantinato Doutora em Educação pela Universidade de São Paulo (USP), campus São Paulo.

Professora do Programa de Pós-

Graduação em Educação da

Universidade Federal Fluminense (UFF), Niterói, RJ, Brasil.

http://orcid.org/0000-0001-8344-2071

$\triangle$ mc_fantinato@id.uff.br

Recebido em 14/04/2021

Aceito em 05/05/2021

Publicado em 26/07/2021

\section{Ethnomathematics in the initial formation of future Mathematics teachers: revealing looks and brands}

Abstract: This investigation aimed to analyze the marks left by Ethnomathematics in the Mathematics Degree. This study was based on the theoretical frameworks of Ethnomathematics and Teacher Education. Through the e-MEC, we identified five courses with disciplines whose name had the word Ethnomathematics. We interviewed the professors of these disciplines and applied an electronic questionnaire to students. Research results pointed out some contributions of Ethnomathematics, regarding the breaking of paradigms in relation to the universality of Mathematics and its implications in the teaching and learning perspective of undergraduates. The identified marks were: the need to value the social, economic and cultural context of future students, recognition of Mathematics as a human construction openness to dialogue and the humanization of the educational process.

Keyword: Ethnomathematics. Mathematics teacher initial training. Curriculum.

\section{Etnomatemáticas en la formación inicial de} futuros profesores de Matemáticas: revelando miradas y marcas

\begin{abstract}
Resumen: Esta investigación tuvo como objetivo analizar las notas dejadas por la Etnomatemática en la Licenciatura en Matemáticas. Este estudio se basó en los marcos teóricos de la Etnomatemática y la Formación Docente. A través del e-MEC, identificamos cinco cursos con disciplinas cuyo nombre tenía la palabra Etnomatemática. Entrevistamos a los profesores de estas disciplinas y aplicamos un cuestionario electrónico a los estudiantes. Los resultados de la investigación señalaron algunos aportes de la Etnomatemática, en cuanto a la ruptura de paradigmas en relación a la universalidad de la Matemática y sus implicaciones en la perspectiva de enseñanza y aprendizaje de los estudiantes de pregrado. Las marcas identificadas fueron: la necesidad de valorar el contexto social, económico y cultural de los futuros estudiantes, el reconocimiento de la Matemática como una construcción humana, la apertura al diálogo y la humanización del proceso educativo.
\end{abstract}

Palabras clave: Etnomatemática. Formación inicial del profesorado de matemáticas. Currículum. 


\section{Introdução}

Este artigo é baseado em alguns resultados da tese de doutorado intitulada "Etnomatemática e suas marcas na Formação Inicial dos futuros professores de Matemática" (SOARES, 2020), desenvolvida pela primeira autora deste texto sob orientação da segunda autora. Tal pesquisa buscou analisar as contribuições de uma disciplina do currículo - que traz no seu título a palavra Etnomatemática - na formação dos licenciandos em Matemática.

Quando falamos em marcas nos vem a ideia de traço, sinal ou impressão deixada por alguém ou algo, e é neste sentido que nosso trabalho se insere, na busca por identificar quais as marcas que a Etnomatemática deixa nos alunos que a vivenciaram e nos professores que são responsáveis por esse componente curricular.

Este trabalho, em particular, tem como objetivo destacar a quebra de paradigmas em relação a universalidade da Matemática, oportunizada pelas discussões e reflexões realizadas no contexto da disciplina da graduação atrelada à Etnomatemática. Nossa pesquisa indicou que os graduandos começam a perceber a Matemática como uma construção humana, além de também revisitarem suas perspectivas de ensino e aprendizagem no tange a abertura para o diálogo e a valorização dos diversos saberes. A perspectiva etnomatemática apresentada na disciplina também parece proporcionar aos alunos o questionamento de algumas crenças que eles trazem da sua experiência em relação ao "erro" em Matemática.

É importante ressaltar que nossa perspectiva se aproxima da curricularização da Etnomatemática e não de sua disciplinarização. Ou seja, pensamos a inserção dessa área de conhecimento nos currículos das graduações em uma perspectiva formativa, e não apenas limitada a uma disciplina. Consideramos ser importante que os futuros professores de Matemática tenham um espaço oportunizado para discutir os pressupostos desta área. Diante disso percebemos que um curso de Licenciatura em Matemática que apresenta uma disciplina com a proposta de se discutir questões relacionadas a Etnomatemática, é um curso que sinaliza um olhar sensivel para as culturas e a valorização dos diversos saberes existentes no ambiente escolar.

Neste texto realizamos quatro movimentos. No primeiro, apresentamos algumas considerações em relação a formação de professores e a Etnomatemática. No segundo, trazemos os caminhos metodológicos da pesquisa. No terceiro, discutimos alguns resultados, que sinalizam as marcas deixadas pela Etnomatemática na formação inicial dos professores de Matemática e como a mesma contribui para iniciar uma nova visão de mundo e educação, mais crítica e reflexiva. Os graduandos participantes da pesquisa sinalizam revisitar o conceito de universalidade da Matemática, atribuindo a mesma a marca de ser uma construção social, humana, histórica e 
política. As narrativas dos estudantes apontam ainda que as experiências na disciplina levaram a refletir sobre suas perspectivas de ensino aprendizagem, no que tange as suas crenças em relação ao "erro", a abertura para o diálogo e a valorização dos diversos saberes.

\section{A formação de professores em Matemática e a Etnomatemática}

Ao pensar nos cursos de Licenciatura em Matemática, é importante voltar o nosso olhar para como estão sendo desenhados e propostos esses cursos em nosso país. Para iniciar nosso diálogo sobre a formação inicial dos futuros professores de Matemática, tomaremos como referência uma articulação do trabalho de Fiorentini e Oliveira (2013), que destaca três perspectivas que têm impacto no modo de organizar o processo de formação profissional dos futuros professores de Matemática, com a pesquisa de Gatti e Nunes (2009), que apresenta um estudo sobre algumas matrizes curriculares dos cursos de Licenciatura em Matemática no Brasil.

Segundo Gatti e Nunes (2009), os cursos de Licenciatura em Matemática podem ser divididos em três tipos, de acordo com o desenho da sua matriz curricular. 0 primeiro tipo referese aos cursos que investem em disciplinas de formação específica em Matemática pura. Essa perspectiva também é apresentada por Fiorentini e Oliveira (2013) ao abordar a concepção de prática de formação centrada no conhecimento matemático clássico. Nesse caso, o futuro professor de Matemática terá uma formação profunda no que tange à Matemática pura e pouca familiaridade com questões pedagógicas referentes à escola.

O segundo tipo de curso investe na formação Matemática clássica e na formação pedagógica, propondo um espaço pequeno para as disciplinas relacionadas à Educação Matemática. Essa perspectiva também é sinalizada por Fiorentini e Oliveira (2013) quando afirmam que alguns cursos enfatizam a prática de ensino da Matemática como aplicação de conhecimentos produzidos, dando mais ênfase à dimensão didática e aos processos metodológicos do ensino da Matemática do que à dimensão pedagógica. Nesse caso, os autores acreditam que o professor de Matemática terá uma formação didática consistente, mas que estará pouco conectada com a área específica da Matemática.

O terceiro e último tipo, segundo Gatti e Nunes (2009), oferece disciplinas de formação específica em Matemática pura e disciplinas em Educação Matemática, além de algumas disciplinas relacionadas à Educação. Tal perspectiva de curso se encaixa na prática pedagógica da Matemática vista "como prática social, sendo constituída de saberes e relações complexas que necessitam ser estudadas, analisadas, problematizadas, compreendidas e continuamente transformadas" (FIORENTINI; OLIVEIRA, 2013, p. 921). 
Segundo Gatti e Nunes (2009), os cursos que se encaixam na terceira perspectiva estariam proporcionando vivências mais significativas para a construção da prática pedagógica dos futuros professores de Matemática. As autoras ressaltam, ao analisar as matrizes curriculares, que há desequilíbrio entre a formação específica da Matemática pura e a formação para a docência, e que no estudo notaram pouca ou quase nenhuma formação integradora. Diante dessas concepções, compreende-se que os saberes do futuro professor de Matemática constituem-se de diversas naturezas, pois o professor, na sua atuação profissional, desenvolve uma atividade de relação com suas crenças sobre o sistema educacional, com o mundo, com os sujeitos; enfim, é um saber de relação, como propõe Charlot (2001).

Mantendo o nosso olhar nessa perspectiva, reconhecemos, como Passos (2016) e Vilela (2013), que no campo da Matemática a tensão se dá entre os Matemáticos Acadêmicos e os Educadores Matemáticos, e que essa tensão impacta na determinação dos programas de ensino da formação inicial dos futuros professores de Matemática. Diante disso, ressaltamos a importância de pensar um espaço de diálogo, de resgate da dimensão humana tanto do estudante quanto do professor e a valorização dos diversos saberes no ambiente escolar.

Muitos pesquisadores da área de Educação Matemática vêm discutindo a formação inicial dos futuros professores de Matemática. Segundo Moreira (2004), referindo-se a Kate Crawford e Jill Alder (1996), os professores de Matemática tiveram em sua grande maioria a experiência com o processo de ensino-aprendizagem associado ao modelo tradicional. Esta autora esclarece, que "as suas aprendizagens formais se basearam essencialmente na memorização, no treino de procedimentos rotineiros e, enquanto estudante, não foi na generalidade envolvido na construção da sua própria aprendizagem" (MOREIRA, 2004, p. 32). Realidade próxima também é observada por Domite (2004, p. 419), ao afirmar que "o educando não tem estado de todo fora das propostas de formação de professores, mas também não está dentro". O curso de Licenciatura em Matemática vem sofrendo muitas críticas como essa, que, segundo Fiorentini e Oliveira (2013), são referentes aos

currículos, sobretudo às disciplinas específicas, às metodologias de ensino de aulas, ao distanciamento ou desconexão entre a prática de formação e as práticas de ensinar e aprender na escola básica, à falta do diálogo ou inter-relação entre as disciplinas específicas e as de formação didático-pedagógica, ao isolamento do estágio, entre outras (FIORENTINI; OLIVEIRA, 2013, p. 920).

Entendemos que outra crítica pertinente está associada ao exagero na formação teórica da Matemática, em detrimento de uma formação holística e mais pautada na prática social. Fiorentini (2004), apoiado nas ideias de Shulman (1986), é enfático ao dizer que: 
saber Matemática para ser matemático não é a mesma coisa que saber Matemática para ser professor de Matemática. Ele não defende que o licenciado deva ter uma Matemática inferior ou mais simples que o bacharel. Se, para o bacharel, é suficiente ter uma formação técnico-formal da Matemática - também chamada de formação sólida da Matemática -, para o futuro professor, isso não basta (FIORENTINI, 2004, p. 109).

A formação de professores é um processo complexo, como diz Serrazina (2012, p. 267): "ser professor sempre foi uma profissão complexa. Essa complexidade tem tendência a acentuarse com a incerteza e a imprevisibilidade que caracterizam este início do século XXI". Tal complexidade é visível nos cursos de licenciatura, pois o professor é um profissional que se forma no mesmo espaço em que irá atuar futuramente - a sala de aula.

Segundo Fiorentini (2004), nos cursos de Licenciatura em Matemática percebemos algumas desconexões entre os professores responsáveis pelas disciplinas voltadas para os elementos da Matemática e aqueles responsáveis pelas disciplinas de cunho pedagógico; com isso, muitas vezes os estudantes da licenciatura vivenciam no dia a dia da sua formação, modelos e estratégias pedagógicas diferentes das teorias educacionais. Para Tardif (2002), os futuros professores já vivem nas salas de aulas das escolas e das universidades em torno de 16 anos imersos no processo de ensino-aprendizagem, e essa experiência é formadora, pois os futuros professores internalizam "crenças, valores, representações e certezas sobre a prática do ofício de professor" (TARDIF, 2002, p. 20), o que torna a formação desse profissional ainda mais complexa.

Em geral observamos que, seja na Educação Básica, seja no Ensino Superior, o conhecimento que o estudante traz da sua vida cotidiana não é valorizado no espaço escolar. Tal preocupação vem aparecendo nos textos e entrevistas de vários autores da área da Educação e da Etnomatemática. Paulo Freire, em entrevista com dois educadores matemáticos, gravada em 1996, ressaltou esse aspecto ao afirmar:

A vida que vira existência se matematiza. Para mim, e eu volto agora a esse ponto, eu acho que uma preocupação fundamental, não apenas dos matemáticos mas de todos nós, sobretudo dos educadores, a quem cabem certas decifrações do mundo, eu acho que uma das grandes preocupações deveria ser essa: a de propor aos jovens, estudantes, estudantes homens do campo, que antes e ao mesmo em que descobrem que 4 por 4 são 16, descobrem também que há uma forma matemática de estar no mundo (D'AMBROSIO, FREIRE e DOMITE, 2009).

Diante dessa realidade, é importante conhecer o contexto sociocultural dos estudantes, dos professores e da comunidade escolar, visando proporcionar a experiência de matematizar e de estar no mundo. 
Outro aspecto que foi evidenciado tanto por Freire (2005) quanto por D'Ambrosio (1997) é a certeza de que a educação é um ato político; isso implica que o educador tenha plena consciência das possibilidades políticas de sua prática. Contudo, a formação deficiente dos educadores é um problema apontado pelos dois autores. Nessa direção, D'Ambrosio (1993) faz duras críticas ao sistema de formação docente, principalmente dos professores de Matemática, que, a seu ver, são

\begin{abstract}
carregados de obsolescência e preconceitos inevitáveis, embutidos na formação do professor e na sua própria ação. O conceito de reciclagem e atualização, como uma medida destinada a aliviar esta obsolescência, é absolutamente insuficiente e não atinge esse objetivo. Faz-se necessário um outro professor, formado de outra maneira e com a capacidade de renovar seus conhecimentos como parte integrante de sua preparação profissional. Além disso, um professor conscientizado do seu papel tem sua ação bem mais ampliada é certamente mais empolgante do que a de um mero transmissor de informação na função de professor (D’AMBROSIO, 1993, p. 49).
\end{abstract}

As falhas na formação do educador devem ser analisadas com uma visão mais abrangente do processo. Um educador "conscientizado" precisa ser formado de "outra maneira"; acreditamos que a Etnomatemática, por seu caráter libertador, pode trazer inúmeras contribuições aos futuros professores de Matemática.

Alguns autores da Etnomatemática, como Gerdes (1996), Stillman e Balatti (2001), Domite (2004), Moreira (2004) e Monteiro (2004), sinalizam algumas possibilidades de contribuição da Etnomatemática para a formação inicial dos professores de Matemática. Segundo Gerdes (1996, p. 126), é essencial incluir na formação inicial do professor o desejo e a preocupação deles em "investigar as ideias e as práticas das suas próprias comunidades culturais, étnicas e linguísticas e procurar formas de construir o seu ensino a partir delas [...] e para construir, para entendimento mútuo, o respeito e a valorização das (sub)culturas e atividades". Esse autor enfatiza a necessidade de desenvolver nos futuros professores a busca por conhecer as práticas matemáticas locais e o contexto sociocultural a que ele, os estudantes e a escola onde leciona pertencem.

Stillman e Balatti (2001), complementando a proposta de Gerdes (1996), afirmam que na perspectiva etnomatemática é preciso que o futuro professor de Matemática seja também um pesquisador da sua própria prática, tornando-se um professor pesquisador, desenvolvendo sua capacidade de problematizar e investigar.

Domite (2004) ressalta que um dos pilares da Etnomatemática é a valorização da aprendizagem que o estudante traz do seu cotidiano, é "lidar com as aprendizagens de fora da 
escola e da escola" (DOMITE, 2004, p. 420). Essa postura irá contribuir para que os futuros professores estabeleçam conexões com os estudantes e com outras áreas de conhecimento.

Outro aspecto importante é apresentado por Monteiro (2004) quando afirma que, na perspectiva da Etnomatemática, a escola deixa de ser um espaço ou local de transmissão de conhecimento para ser um espaço de "interlocução entre diferentes saberes". A autora argumenta que

a instituição escola precisa, assim, se preparar para ser, nos próximos anos, mais que um espaço para a difusão do saber; será necessário gerar condições de: interlocução entre diferentes saberes; articulação entre igualdade e diferença, entre tempo e espaço, ou seja [...] a escola está desafiada a ser um espaço de cruzamento de saberes e linguagens, de educação intercultural e construção de uma nova cidadania (MONTEIRO, 2004, p. 436).

A Etnomatemática pode fornecer aos futuros professores de Matemática elementos para ajudá-los a mediar na discussão e no diálogo dos diversos saberes. Enfim, concordamos com Moreira (2004) quando ao afirmar que,

\begin{abstract}
na sua especificidade, o enfoque situa-se ao nível da inclusão do conhecimento etnomatemático na formação inicial de professores e de um desenvolvimento profissional em torno da ideia do professor investigador etnomatemático, isto é, um professor apto a investigar as práticas matemáticas fora da escola e a enquadrá-las e desenvolvê-las pedagogicamente, sendo essencial uma visão transdisciplinar do conhecimento e uma discussão em torno do papel social da escola e da construção do conhecimento escolar (MOREIRA, 2004, p. 9).
\end{abstract}

A autora sinaliza que trazer reflexões acerca do papel social da escola, assim como da construção do conhecimento escolar na formação inicial, pode ampliar a visão de educação dos futuros professores. Diante dessa perspectiva, é necessário que os futuros professores de Matemática possam ter contato com todas as possibilidades, inquietações e fundamentações que emergem da Etnomatemática. Reconhecendo esta perspectiva como elemento potente para uma formação de professores que fomente uma postura e uma prática mais criativas, críticas e reflexivas e voltadas para a especificidade sociocultural dos estudantes, D'Ambrosio (2005), Domite (2004) e Ribeiro (2006) inquietam a todos, ao questionar se essas dimensões de fato vêm sendo abordadas nos cursos de Licenciatura em Matemática.

\title{
3 Caminhos da pesquisa
}

Nossa pesquisa se propôs a compreender um fenômeno que acontece em algumas Universidades públicas do Brasil na formação inicial dos futuros professores de Matemática, mas 
sem deixar de considerar o todo que envolve essa temática. Esse processo se iniciou com muitas leituras, reflexões, questionamentos e na busca por meios e procedimentos técnicos que nos ajudassem a compreender melhor a realidade.

De início, foi feito um levantamento das Universidades públicas do Brasil que possuíam ativo o Curso de Licenciatura em Matemática em 2018, por meio de consulta à base de dados do e-MEC. Esta escolha deu-se pelo fato do e-MEC ser a base de dados oficial de informações relativas às Instituições de Educação Superior - IES e cursos de graduação do Sistema Federal de Ensino no Brasil. Neste site é facultativo as IES do Sistema Estadual de Ensino fazer parte do cadastro do e-MEC.

Após esse levantamento, passamos para a segunda etapa, que consistiu em identificar que cursos possuíam disciplinas apresentando no nome a palavra Etnomatemática. Para essa identificação foi feita uma busca por meio das matrizes curriculares ou Projeto Pedagógico do Curso de cada IES, ressaltando que para as IES que possuem cursos de Licenciatura em Matemática em campi diferentes, acessamos a matriz curricular disponibilizada na página eletrônica de cada campus. As IES que não disponibilizaram o Plano Pedagógico do Curso ou a matriz curricular foram desconsideradas, devido à ausência de informações. Optamos por estabelecer como critério que a disciplina de Etnomatemática fosse ofertada aos alunos nos anos de 2018 ou 2019. A partir desses parâmetros fixados, encontramos cinco Cursos de Licenciatura em Matemática de universidades públicas do Brasil que possuíam em sua matriz curricular uma disciplina com a palavra Etnomatemática no título. Apresentamos a seguir as universidades que foram identificadas nesse levantamento.

Quadro 1: Universidades e seus componentes curriculares.

\begin{tabular}{|c|c|c|c|}
\hline Universidade & Campus & Região & Componente Curricular \\
\hline Universidade Federal de Uberlândia & Pontal & Sudeste & Matemática e cultura: Etnomatemática \\
\hline $\begin{array}{c}\text { Universidade Estadual do Rio de Janeiro- } \\
\text { Faculdade de Educação da Baixada } \\
\text { Fluminense }\end{array}$ & $\begin{array}{c}\text { Baixada } \\
\text { Fluminense }\end{array}$ & Sudeste & Cultura e Etnomatemática \\
\hline $\begin{array}{c}\text { Universidade Estadual Paulista Júlio de } \\
\text { Mesquita }\end{array}$ & $\begin{array}{l}\text { Ilha } \\
\text { Solteira }\end{array}$ & Sudeste & Etnomatemática \\
\hline Universidade Federal de São João del Rei & $\begin{array}{l}\text { São João } \\
\text { del Rei }\end{array}$ & Sudeste & Etnomatemática \\
\hline Universidade Federal Fluminense & $\begin{array}{l}\text { Santo } \\
\text { Antônio de } \\
\text { Pádua }\end{array}$ & Sudeste & $\begin{array}{c}\text { Educação Matemática e } \\
\text { Etnomatemática }\end{array}$ \\
\hline
\end{tabular}

Fonte: autoras, 2018. 
No quadro 1 podemos notar uma predominância dos cursos localizados na região Sudeste. Tal fato pode ser explicado por fatores históricos, tendo havido no Brasil maior concentração de universidades e grupos de pesquisa ${ }^{1}$ no Sudeste, e o movimento de expansão para outras regiões brasileiras ser ainda recente. Existe também a possibilidade de haver alguma dificuldade das universidades de manterem seus cadastros atualizados no e-MEC e no site oficial da instituição. Outro fator pode estar relacionado com 0 fato de 0 cadastro das universidades públicas estadual ser facultativo nessa plataforma, nesse sentido algumas instituições estaduais podem não ter sido contempladas. Estamos cientes de que esta amostra obtida pode não representar a totalidade de cursos de Licenciatura de Matemática do Brasil que apresentem um componente curricular com foco na Etnomatemática, mas pode servir como um retrato desta realidade.

Na busca por identificar, na perspectiva dos sujeitos, quais são as contribuições da Etnomatemática para a formação docente, ouvimos os professores que ministraram a disciplina de Etnomatemática e os alunos que já cursaram essa disciplina. Nesse sentido, de cada curso, elegemos como sujeitos da pesquisa o professor atual da disciplina e alunos que já cursaram essa disciplina. Tivemos ao todo 37 sujeitos para a pesquisa: 5 professores que lecionam a disciplina Etnomatemática e 32 alunos que já cursaram a mesma.

Como metodologia de análise de dados optamos pela Análise Textual Discursiva, pois esse processo é considerado uma tempestade de ideias e nos possibilita visualizar novas conexões e relações aos fenômenos estudados (MORAES, 2003). A primeira etapa dessa metodologia implicou em reunir um conjunto de informações sistematizadas em forma de texto ou outras representações gráficas, e recebe o nome de Corpus. A etapa seguinte foi a desconstrução, fase em que ocorreu a derivação do Corpus em elementos textuais significativos na busca pela emersão das unidades de análise, tendo como parâmetro os objetivos da pesquisa. Posteriormente foi feita a categorização, na tentativa de estabelecer articulações entre as unidades de análise. Na última etapa foi construído um texto interpretativo a partir das categorias.

Nesse artigo apresentaremos apenas uma síntese parcial das entrevistas feitas com os professores participantes da pesquisa, assim como das respostas do questionário proposto aos alunos. Optamos por representar os sujeitos da pesquisa como Estudante 1, Estudante 2... de acordo com a ordem que responderam o questionário, e atribuímos a primeira letra do nome do seu professor após o número; por exemplo, Estudante $1 \mathrm{G}$ significa o primeiro estudante que

\footnotetext{
${ }^{1}$ Cadastrados no Diretório dos Grupos de Pesquisa no Brasil do Conselho Nacional de Desenvolvimento Científico e Tecnológico.
} 
respondeu o questionário e é aluno da professora Georgia. Conforme acordado com os professores entrevistados, utilizamos nomes fictícios para representá-los. Os professores participantes foram denominados de Carla, Denise, Fábia, Georgia e Joaquim.

\title{
4 Quebrando paradigmas em relação a universalidade da Matemática: a Matemática como uma construção humana
}

Reconhecer o processo de formação inicial dos futuros professores de Matemática, na disciplina de Etnomatemática, nos possibilita identificar quais concepções de Matemática emergiram na pesquisa e apontam uma quebra de paradigma. Na perspectiva d'ambrosiana, a Matemática escolar também pode ser considerada como uma Etnomatemática e assume "um caráter de universalidade, sobretudo devido ao predomínio da ciência e tecnologia modernas, que foram desenvolvidas a partir do século XVII na Europa" (D'AMBROSIO, 2008, p.7). Este autor apresenta o ensino de Matemática como eurocêntrico e universal. A Etnomatemática vem se contrapondo a essa perspectiva, evidenciando a necessidade de valorizar os saberes e fazeres de diversos grupos sociais. Entre os estudantes das universidades participantes, alguns deixaram emergir em seus discursos questões envolvendo a "universalidade da Matemática". O estudante $6 \mathrm{G}$ fala que:

\begin{abstract}
A disciplina foi de grande valia para a minha formação, pois pude refletir a respeito da matemática que é ensinada até os dias atuais, e de poder ter contato com "outras matemáticas", além da trazida pelos europeus. Me fez refletir que cada um de nós temos algo a agregar a esse campo independente de ter feito uma graduação ou de ter contato com a escola, pois cada um devido as circunstâncias da vida aprender algo para sobreviver e isso deve ser valorizado. (Estudante 6 G, 2019).
\end{abstract}

Esse estudante reconhece a importância dos saberes e fazeres da escola, bem como dos relacionados ao cotidiano de cada aluno. D'Ambrosio (2005) nos apresenta as tensões e as relações de poder no campo da Matemática no que tange a busca por invisibilizar a matemática do dia a dia. A valorização de outras matemáticas perpassa primeiro a disposição em conhecer outras formas de pensar, medir, quantificar, enfim, outras formas de estar e permanecer no mundo.

A estudante $5 \mathrm{~J}$ conta que a disciplina "foi muito legal, aprendi várias coisas diferentes e descobri que existe outros tipos de matemática sem ser a matemática acadêmica" (Estudante 5J, 2019). Os estudantes $25 \mathrm{D}$ e $13 \mathrm{~J}$ corroboram essa descoberta, ao afirmarem que "pude repensar o conceito de matemática universalizada" (Estudante 25 D, 2019) e "Foi uma ótima matéria pra sair do conceito de matemática acadêmica, coisa que eu não enxergava" (Estudante 13 J, 2019). Percebemos nesses discursos que o encontro com outras matemáticas impactou a concepção 
desses estudantes no que diz respeito à "universalidade da matemática acadêmica". Para Barton (2004, p. 55), "a etnomatemática, de fato, cria uma ponte entre a matemática e as ideias (e conceitos e práticas) de outras culturas". O estudante $14 \mathrm{G}$ revela nesse sentido que "a Etnomatemática é um programa onde se procura valorizar as diferentes matemáticas, desenvolvidas por trabalhadores como pedreiros e costureiras, e procura desenvolver essas matemáticas em contrapartida à supervalorização da matemática acadêmica" (Estudante $14 \mathrm{G}$, 2019).

Reconhecer que a Matemática não é universal pode ajudar na postura dos futuros professores em sala de aula, como afirma a estudante $5 \mathrm{~J}$ : "Foi muito importante para o meu desenvolvimento enquanto professora daqui a uns anos. Aprendi que existem vários tipos de matemática e não só uma" (Estudante 5 J, 2019). Complementando essa ideia, Bicudo (2005) ressalta que o professor de matemática não deve concebê-la como algo isolado e sem relação com homem e com o mundo. A partir dessa ideia de Bicudo (2005), identificamos outra marca apresentada pelos estudantes nessa pesquisa, relacionada à percepção de mundo e de Matemática. $O$ estudante $23 \mathrm{D}$ revela que a disciplina foi "um aprendizado que fará muita diferença na minha graduação e na percepção de mundo e até mesmo em relação à matemática e sua construção [...], trouxe uma visão que eu nunca imaginei que a matemática poderia tomar" (Estudante 23 D, 2019). Baraldi (1999) ajuda a entender que a Matemática é uma construção humana e não pode estar desassociada dela, ao nos advertir que

O conhecimento matemático não pode ser separado do conhecimento empírico, da física e das outras crenças. Desse modo, a Matemática está inserida na história e prática humana e, portanto, não pode ser separada de ciências humanas e sociais ou de considerações culturais, em geral (BARALDI, 1999, p. 89).

Já a fala dos estudantes $23 \mathrm{D}$ e $21 \mathrm{D}$, indica entenderam a Etnomatemática como

um ato de preservação mesmo, de matemáticas que vieram sendo sempre oprimidas referente a uma em específico. Disciplina que trata a matemática como ela é, uma construção histórica, um produto humano, cheio de fator humano (Estudante $23 \mathrm{D}$, 2019);

uma palavra com conceito amplo, entendo que a etnomatemática vai observar as culturas, as matemáticas produzidas ali, entender o porquê é daquela maneira e tentar conscientizar todos que não há uma matemática melhor que a outra e sim matemáticas, produzidas por pessoas (Estudante 23 D, 2019).

As narrativas desses apontam a compreensão da Etnomatemática como uma construção humana, perspectiva esta que dialoga com D'Ambrosio (2005). A professora Denise, em sua 
entrevista, corrobora também esse aspecto quando diz que "a Etnomatemática vem para reforçar a dimensão humana da formação do professor. Ela vem reforçar a questão cultural para além da burocrática, ela vem para falar das relações humanas para além das institucionais, ela vem falar de cultura, vem falar de gente" (Entrevista com Denise, 2019). Essa aproximação com a dimensão humana auxiliou o estudante $16 \mathrm{D}$ a conseguir responder a um questionamento antigo,

\begin{abstract}
um questionamento constante que eu tinha era o que responder se me perguntassem o que era matemática. Após enxergar e refletir sobre as diversas Matemáticas e sobre um lado mais humano que elas podem ter, consegui mudar minha antiga concepção sobre Matemática e hoje a encaro com uma construção social.
\end{abstract}

A estudante $28 \mathrm{G}$ completa essa ideia dizendo que "a matemática deve ser compreendida não apenas como uma constituição social, mas também como uma construção histórica e política" (Estudante 28 G, 2019). D’Ambrosio (2008, p. 13) ressalta que "a invenção matemática é acessível a todo indivíduo, e a importância dessa invenção depende do contexto social, político, econômico e ideológico." Nessa perspectiva pedagógica, Ferreira (1992) afirma que a Etnomatemática

[...] resgata o real vivido e o transforma, melhor dizendo amplia esse real, respeitando a existência de cada aluno. Minhas experiências (...) mostram que a matemática dita institucional perde seu estado de "verdade absoluta" para se transformar no que de fato é, uma criação humana (FERREIRA, 1992, p. 8).

A Etnomatemática não tem a intenção de substituir a Matemática institucional, mas sim promover o diálogo dos diversos saberes/fazeres que podemos associar à Matemática. A proposta é trazer esses diferentes saberes/fazeres para o encontro e o diálogo.

Diante das falas desses estudantes, podemos perceber que as disciplinas incorporaram espaços e diálogos que promoveram a reflexão acerca da universalidade da Matemática, evidenciando que a sua supervalorização deve ser revista, e que deve ser atribuída à Matemática a marca de ser uma construção social, humana, histórica e política. E quais as implicações pedagógicas a Etnomatemática deixou nos estudantes dessa disciplina?

\title{
5 A Etnomatemática e suas implicações na perspectiva de ensino-aprendizagem dos estudantes
}

Monteiro e Mendes (2014) trazem algumas reflexões acerca das possíveis implicações pedagógicas da Etnomatemática para a prática escolar. Qual modelo de escola essa perspectiva inspira? Que saberes são silenciados na escola? Como promover um ambiente escolar democrático? Tais questionamentos têm gerado debate entre os pesquisadores da área, como 
Domite (2000), Moreira (2009) e Fantinato e Soares (2018). Percebemos nos discursos dos estudantes desta pesquisa uma grande preocupação nesse sentido.

A Estudante $8 \mathrm{D}$ menciona que a disciplina Etnomatemática foi uma das "poucas matérias em que discutimos diferenças culturais e como isso se relaciona com a educação" (Estudante 8 D, 2019). Segundo Gerdes (1996, p. 126), é essencial incluir na formação inicial do professor 0 desejo e a preocupação deles em "investigar as ideias e as práticas das suas próprias comunidades culturais, étnicas e linguísticas e procurar formas de construir o seu ensino a partir delas [...] para construir, para entendimento mútuo, o respeito e a valorização das (sub)culturas e atividades". Esse autor enfatiza a necessidade de desenvolver nos futuros professores a busca por conhecer as práticas matemáticas locais e o contexto sociocultural ao qual eles, os estudantes e as escolas onde lecionam pertencem. Reconhecendo a escola como o encontro de diversas culturas e sujeitos conforme sinaliza Monteiro (2004), percebemos indícios de que a formação inicial de Matemática ainda oferece poucos espaços para a reflexão dessa temática.

Nesse contexto, 0 Estudante $14 \mathrm{G}$ ressalta que a disciplina "ajudou a desenvolver um olhar mais crítico para diversas questões vividas na sala de aula" (Estudante 14 G, 2019). Essa perspectiva dialoga com Fantinato, Freitas e Marchon (2018, p. 221), quando destacam "a necessidade de trabalhar, durante a formação docente inicial ou continuada, uma organização crítica da realidade". Essa criticidade pode estar relacionada à valorização e ao reconhecimento dos diversos sujeitos e relações presentes na escola. A Estudante $26 \mathrm{G}$ apresenta a Etnomatemática como "uma proposta educacional para o ensino da Matemática que visa estimular a criatividade, valorizar a cultura e o ambiente social do aluno e adequar aquilo que se deseja transmitir" (Estudante $26 \mathrm{G}, 2019$ ). Tal proposta de remodelar o ensino da Matemática conversa com as ideias de D'Ambrosio, quando este propõe que

A Etnomatemática apresenta-se, assim, não como uma nova disciplina, mas como
uma prática pedagógica. Não se trata da substituição da Matemática acadêmica, mas
sim de facilitar ao indivíduo, a partir do domínio da sua Etnomatemática, a aquisição
das partes da Matemática acadêmica que Ihes são interessantes e úteis. [...] A
Etnomatemática propõe uma pedagogia viva, dinâmica, de fazer o novo em resposta
a necessidades e estímulos ambientais, sociais, culturais (D’AMBROSIO, 2008, p. 9).

A busca por pensar 0 ensino da Matemática de forma diferenciada também é a preocupação da Estudante $19 \mathrm{G}$ e da Estudante $22 \mathrm{~J}$. Elas ressaltam que a Etnomatemática "é 0 ramo cientifico que buscar melhorar o ensino da Matemática nos dias atuais [...] ela me ajudou a compreender que, em grande parte dos casos, um plano deve se adequar aos alunos e não 0 contrário" (Estudante 19 G, 2019); a Etnomatemática "me inspirou novas formas de abordagem 
para a Matemática em sala" (Estudante $22 \mathrm{~J}, 2019)$. Nessa nova abordagem inspirada pela Etnomatemática, é interessante que o professor fortaleça as raízes culturais dos seus estudantes, visando fornecer uma aprendizagem mais significativa, como sinaliza Domite (2000) ao dizer que,

no que se refere a uma pedagogia pela via da etnomatemática, propriamente dita, é natural pensarmos a formação de professores/as voltada não apenas para uma visão da Matemática e das formas que favorecem a sua apropriação pelos alunos/as, mas também para a atualização científica e pedagógica geral da matemática que está aí (DOMITE, 2000, p. 47).

Segundo a autora, ao pensar nessas novas possibilidades, o professor tem a oportunidade de revisitar a prática pedagógica e produzir novas pesquisas e estudos que irão contribuir para a área de Educação Matemática.

D’Ambrosio (2005, p. 23) sinaliza que "práticas apreendidas fora do ambiente escolar podem contribuir para uma visão crítica da realidade". Essa preocupação em dialogar com os saberes cotidianos dos estudantes também foi evidenciada por diversos estudante na pesquisa. Acreditamos que tal reflexão tenha sido o legado dessa disciplina. Algumas falas dos estudantes relacionadas abaixo mencionam essa concepção:

Que é um projeto pedagógico que busca aproximar o aluno da matemática, de maneira que você aproxime a matemática da sua vida, da sua cultura, pois se faz matemática constantemente sem perceber. [...] Foi de grande aprendizado passar a olhar para 0 seu aluno como único, com toda a sua bagagem e cultura e poder pensar em estratégias de colocar a matemática dentro da vida dele e não o contrário (Estudante $32 \mathrm{G}, 2019)$.

A disciplina me ensinou a observar as várias maneiras de ensino e de aprendizagem e a valorizá-las de forma única e igual, respeitando a individualidade e a diversidade de cada aluno e levando em consideração a sua cultura e seu meio social (Estudante $4 \mathrm{~J}, 2019)$.

Sim, a etnomatemática me fez ver o mundo com outros olhos e entender que acima de todos os conhecimentos existe a necessidade de saber muito mais do dia a dia e das culturas dos nossos alunos (Estudante 24 D, 2019).

Esses discursos revelam a valorização do contexto social, econômico e cultural em que 0 estudante está inserido, assim como a preocupação em conhecer mais de perto cada um deles. Essa ideia dialoga com Domite (2004), que afirma que a formação de professores de Matemática em uma perspectiva etnomatemática tem,

[...] como pressuposto básico para a formação de professores numa perspectiva da etnomatemática, a tentativa de tornar o professor e a professora de matemática mais disponiveis para conhecer mais intimamente 0 aluno e a aluna, em suas especificidades como condições sócio-econômicas, preferências, situação familiar, 
conhecimentos anteriores (intelectuais, artísticos, entre outros) que fazem parte do seu grupo-sala (DOMITE, 2004, p. 428, grifo da autora).

Tudo indica que essa característica apresentada por Domite representa uma das marcas mais descritas na visão dos estudantes em relação à disciplina Etnomatemática. Interagimos ainda com Moreira (2014), que corrobora a perspectiva acima e ressalta um

dos pilares fundamentais do enquadramento da abordagem Etnomatemática da atualidade: as dinâmicas locais e o ritmo da cultura local, para que as propostas pedagógicas se enraízem nas realidades locais e trabalhem os contextos sociais e culturais onde se encontram os estudantes e formandos (MOREIRA, 2014, p. 33).

É importante pensar uma proposta pedagógica tendo um olhar sensível para os estudantes e para o contexto em que a escola está inserida. $\mathrm{O}$ Estudante $9 \mathrm{~F}$ relata que "muitos educadores tendem a não considerar os 'saberes' populares, dando validade apenas aos conhecimentos acadêmicos". Ao revelar que "muitos educadores tendem a não considerar os 'saberes' populares", o estudante denuncia que na escola os saberes oriundos de contextos informais não são valorizados, o que pode representar empobrecimento das possibilidades de uma proposta no processo de ensino-aprendizagem. Ele revela ainda que "a disciplina Etnomatemática traz uma visão mais inclusiva e de maior respeito pelos conhecimentos populares, ajudando a preservar as belezas do pluralismo cultural" (Estudante $9 \mathrm{~F}, 2019$ ). Ele sinaliza nessa fala que a Etnomatemática impulsiona uma "visão mais inclusiva", que fomenta olhares outros para a questão da diversidade, o que nos faz recordar as orientações de Vergani (2000) em relação à formação de professores:

Os professores deverão ser formados, e não só sensibilizados, para uma correta integração dos alunos nos padrões do desenvolvimento atual que comportam não só novas formas de produção como novos tipos de relações socioeconômicas. As suas competências profissionais deverão ser orientadas pela consciência de uma missão mais vasta - e certamente mais entusiasmante - do que mera transmissão de conhecimento -"ready made" (VERGANI, 2000, p. 39).

Essa busca por uma formação de professores que impulsione o desejo de pensar e repensar o ensino da Matemática, visando promover transformações e novos horizontes, esbarra nas ponderações feitas pelo Estudante $6 \mathrm{G}$ :

A disciplina foi muito boa, porém eu percebo que, para a vida real mesmo, para aplicar nas escolas, dependendo do que fosse feito, seria mais difícil, pois toma muito tempo e dedicação, fora que geralmente professor não tem essa carga horária assim disponível. Teríamos que rever o sistema de ensino (Estudante 6 G, 2019). 
Compreendemos os argumentos do Estudante $6 \mathrm{G}$ e reconhecemos que, de fato, propor outros caminhos demanda muito estudo e tempo. Mesmo diante desses obstáculos, Vergani (2000) convida a ter a

consciência de que a Etnomatemática tem uma missão no mundo de hoje que transcende o interconhecimento das alteridades socioculturais. Cabe-lhe apontar um caminho de transformação crítica das nossas próprias comunidades ocidentais, solidariamente abertas a outras formas de refletir, de sentir e de agir (VERGANI, 2000, p. 7).

Ao conceber outras "formas de refletir, de sentir e de agir", como propõe a autora, os futuros professores podem ressignificar sua concepção de escola, suas relações com os sujeitos que estão envolvidos no fazer da escola e no entorno, seu papel como professor, suas condições de trabalho, ao estarem abertos a novos questionamentos e novas formas de refletir e agir. Nesse sentido, por muito tempo na Matemática a "associação entre o erro e o fracasso se apresenta à nossa mente quase como um substantivo composto ou binômio, que culmina na reprovação do aluno" (CARVALHO, 1997, p. 11). O erro em alguns espaços ainda é visto como "um não saber", e a organização de cálculos de forma diferente também é vista como inadequada. Alguns estudantes revisitaram esses conceitos e revelaram que

sei que quando estiver dentro de sala de aula saberei entender quando o meu aluno tiver o novo jeito de fazer uma conta e não acharei que está errado (Estudante $5 \mathrm{~J}$, 2019).

A partir desta e de uma outra disciplina, consegui interligá-las para entender que cada aluno tem seu jeito de entender um conteúdo e que não necessariamente está errado, e isso de julgar o aluno que pensa diferente está errado, é por causa do entendimento do aluno licenciando de que o conhecimento acadêmico é o único correto (Estudante 12 J, 2019).

Diante desses discursos, podemos inferir que tais futuros professores começaram a questionar algumas crenças que trazem em relação ao "erro". Segundo Tardif (2002), os saberes temporais são aqueles construídos ao longo do tempo e que ocorrem por meio de modelos, pois boa parte do que os professores sabem sobre o ensino tem origem na própria vida escolar, em decorrência dos conhecimentos, crenças e certezas já construídos. 0 autor ressalta que, ao começar a lecionar, o professor reativa as crenças e maneiras de fazer que ele vivenciou na época escolar para solucionar os problemas profissionais aos quais se depara (TARDIF, 2002).

Ao iniciar seu trabalho como professores, os indivíduos tiveram em média dezesseis anos de convívio com diversos professores e com várias crenças que permeiam o espaço escolar. Segundo Tardif, em geral, os estudantes passam pelos cursos de formação sem conseguir 
ressignificar algumas das suas crenças no que diz respeito ao ensino e, quando começam a lecionar, resgatam esses modelos para resolver os problemas do cotidiano escolar. Diante dessa realidade, identificamos indícios de que os estudantes de nossa pesquisa já iniciaram o processo de ressignificação de algumas crenças em relação ao ensino durante a disciplina Etnomatemática. No que tange ao "erro", eles sinalizaram que, ao se tornarem professores, estarão abertos a compreender o modo de pensar de seus futuros estudantes, visando auxiliá-los no processo de ensino-aprendizagem.

Essa preocupação em entender o aluno, entender o seu "fazer matemático", como citado pelo Estudante $25 \mathrm{D}$, revela uma perspectiva diferente de olhar para a escola e os processos educacionais. Nesse sentido, alguns estudantes revelaram que a Etnomatemática modificou suas concepções acerca do ensino de Matemática. 0 Estudante $28 \mathrm{G}$ afirma que a Etnomatemática "contribuiu para melhorias desse ensino, dialogando e trazendo novos saberes" (Estudante $28 \mathrm{G}$, 2019); o Estudante 26 G é assertivo ao dizer que as marcas deixadas nele estão atreladas à relação entre professor e estudante; ele fala que

\begin{abstract}
auxiliou bastante em relação aos vínculos que nós, como futuros professores, precisamos manter com os alunos e com todos os envolvidos no processo educacional. Aprendi a ter um olhar mais empático, valorizar as diferenças, contextualizar os conteúdos abordados e assim transformar a sala de aula em um ambiente inclusivo e agradável para todos (Estudante 26 G, 2019).
\end{abstract}

Essa transformação da sala de aula em "um ambiente inclusivo e agradável" também é sinalizada pela Estudante $10 \mathrm{~J}$, ao afirmar que a sala de aula não deve ter um "caráter opressor" e que essa também foi uma marca deixada. Segundo ela, "a etnomatemática desperta no educador 0 entendimento de que existem formais plurais de lidar com algo. Isso faz com que nossa prática em sala de aula não tenha um caráter opressor" (Estudante $10 \mathrm{~J}, 2019)$. Esses podem ser indícios de que esses estudantes percebem o impacto que a educação tem na vida das pessoas. Cortella (2006) afirma, nesse sentido, que a Educação é essencial, pois,

ao contrário dos outros seres vivos, nós, os humanos, dependemos profundamente de processos educativos para a nossa sobrevivência (não carregamos em nosso equipamento genético instruções suficientes para a produção de existência), desse prisma, a Educação é instrumento basilar para nós (CORTELLA, 2006, p. 49, grifos do autor).

Com essas considerações, é oportuno reconhecer que o ambiente de sala de aula democrático, agradável e pautado no diálogo, pode fomentar sujeitos críticos e respeitosos à 
diversidade. A formação inicial de professores de Matemática também pode ser um espaço com essas características, como sinaliza o estudante $16 \mathrm{D}$, ao afirmar que

a disciplina de Etnomatemática contribuiu tanto para minha formação pessoal quanto nas minhas atuações profissionais. Consigo ser mais sensível, reflexivo e flexível enquanto professor. Apesar de ter um currículo para cumprir, tenho o dever de pelo menos apresentar as outras matemáticas e, enquanto estiver atuando com a nossa Matemática usual, ser o mais humano e compreensível possível (Estudante $16 \mathrm{D}$, 2019).

Ele sinaliza que a disciplina contribuiu não só para sua formação profissional, mas também para sua formação como pessoa, enfatizando a importância das relações humanas no processo de ensino-aprendizagem. Segundo Fantinato (2004),

a Etnomatemática desmistifica o caráter universal, a-histórico da matemática escolar, porque vê a matemática como uma produção cultural, contextualizada; analisa, portanto, a sua presença nos contextos da vida cotidiana. [...] Esse reconhecimento passa a ser uma ferramenta poderosa no resgate da autoestima do aluno, que, como se sabe, é favorecedora da aprendizagem (FANTINATO, 2004, p. 177-178).

A autora enfatiza a busca da valorização do outro, o que, segundo ela, pode potencializar a aprendizagem. Essa perspectiva dialoga com D'Ambrosio, quando este afirma que a Etnomatemática visa uma formação integral do indivíduo e no desenvolvimento da criatividade (D'AMBROSIO, 2008).

Os Estudantes $6 \mathrm{G}$ e $1 \mathrm{G}$ apresentaram a necessidade de propor uma nova organização das atividades, outras formas de avaliar e outras possibilidades de metodologias de ensino.

\begin{abstract}
Ainda não dou aula, mas de certa forma irá contribuir, porque hoje em dia estamos acostumados ao jeito tradicional de ensino, onde o professor diz e o aluno obedece, e nós precisamos mudar isso, precisamos reconhecer, respeitar e aceitar a cultura do aluno como conhecimento valido a ser trabalhado em sala de aula. Temos que trabalhar com a etnomatemática e buscar entender os procedimentos utilizados pelos alunos para a construção do conhecimento; o professor não deve impor o caminho a ser percorrido (Estudante $1 \mathrm{G}, 2019$ ).
\end{abstract}

As propostas apresentadas pelos estudantes remetem às novas tendências para a Educação. Nesse sentido, Moreira (2004) ressalta que a inclusão do conhecimento etnomatemático na formação inicial do futuro professor de Matemática pode gerar a ideia do professor investigador etnomatemático "isto é, um professor apto a investigar as práticas matemáticas fora da escola e a enquadrá-las e desenvolvê-las pedagogicamente, sendo essencial uma visão transdisciplinar do conhecimento e uma discussão em torno do papel social da escola e da construção do conhecimento escolar (MOREIRA, 2004, p. 9). 
Nesse sentido o professor não se coloca como "dono do saber", mas assume uma postura de orientador, de designer de experiências de aprendizagem. Essa postura do professor como orientador foi sinalizada como uma contribuição pelo Estudante $2 \mathrm{G}$ :

Como estou em um curso de licenciatura preciso saber como trabalhar em sala de aula, e a disciplina proporcionou-me diferentes abordagens e teorias a serem usadas como futuro lecionador, assim será possível colocar na prática as teorias aprendidas. Além disso, a professora sempre buscou saber a opinião da turma, nos perguntava como gostaríamos de trabalhar e sempre abria rodas de conversa então conseguíamos saber a opinião dos outros alunos e aprendíamos com eles também. Então percebemos que nesse sentido a professora deixava de ser a dona do saber $\mathrm{e}$ passava a ser um membro do nosso grupo, assumindo uma postura de orientador, existindo assim o diálogo simétrico, e isso marcou minha formação acadêmica (Estudante 2 G, 2019).

O estudante ressalta que a postura da professora Georgia deixou marcas na sua formação, uma vez que ela assumiu junto à turma uma postura de orientadora, o que possibilitou e fomentou o diálogo. Tal observação se aproxima das ideias de Fiorentini (2004), ao afirmar que: "O professor de cálculo, álgebra ou análise acredita que ensina apenas conceitos e procedimentos matemáticos; ele geralmente não percebe que ensina também um jeito de ser professor" (FIORENTINI, 2004, p. 1).

De forma análoga, podemos dizer que o modo como o professor de Etnomatemática propõe a disciplina pode também influenciar a prática do futuro professor de Matemática, conforme sinalizado pelo Estudante $2 \mathrm{G}$. Ao nos debruçarmos sobre as respostas do questionário, fomos surpreendidas pela Estudante $10 \mathrm{~J}$, ao dizer que:

a faculdade estava perdendo sentido, pois estava tendo contato com apenas um tipo de produção de conhecimento (matemática acadêmica de caráter eurocêntrico). Quando entendi a proposta do Programa Etnomatemática, me identifiquei e me encontrei como educadora matemática (Estudante $10 \mathrm{~J}, 2019)$.

Esse encantamento com a docência a partir da Etnomatemática também se mostrou presente e recorrente no dia 23 de julho de 2020, quando a primeira autora apresentou os resultados parciais da pesquisa à turma da professora Denise. Durante o diálogo com a turma, após a fala inicial, um estudante fez oralmente o seguinte comentário: "O contato com a etnomatemática me fez querer ser professor", o que gera assim mais um indício de que o contato com uma perspectiva de Educação mais humana, mais crítica e menos excludente pode inspirar novos educadores matemáticos. 


\section{Considerações finais}

A pesquisa sinalizou para algumas marcas da etnomatemática na formação inicial, do ponto de vista dos alunos que participaram da pesquisa. A abertura para o outro é uma marca deixada pela vivência das discussões e reflexões em torno da Etnomatemática. Nesse sentido conhecer 0 outro que está em um contexto diferente, se torna uma necessidade. Esse movimento pode levar os graduandos a se tornarem mais empáticos ao outro, mais abertos ao diálogo com 0 outro e para saberes outros.

É importante ressaltar que esse outro pode ser um membro de uma comunidade de prática, ou de grupo social ou de outra etnia, ou o estudante que está presente na sala de aula. É relevante que o futuro professor reconheça o seu futuro estudante como um outro potente. Com base em nossas análises, percebemos que os graduandos reconheceram essa perspectiva e apontaram para a necessidade da valorização do contexto social, econômico e cultural em que seus futuros estudantes estarão inseridos, e se mostram preocupados em conhecer mais de perto cada um deles, conforme sinalizado por Domite (2004).

A nossa pesquisa indica que as reflexões feitas durante as aulas possibilitaram que os graduandos pudessem revisitar suas crenças em relação ao "erro" e sinalizar que ao se tornarem professores estarão abertos a compreender os modos de pensar de seus futuros estudantes. Em relação a universalidade da Matemática, os futuros professores reconheceram que a Matemática é uma das etnomatemáticas existentes, e que durante as aulas tiveram a oportunidade de conhecer "outras matemáticas" superando a ideia de que a Matemática institucionalizada é única e universal, atribuindo a Matemática a marca de ser uma construção social, humana, história e política.

Reconhecendo as marcas que a disciplina Etnomatemática deixou nos estudantes da Licenciatura em Matemática, no que tange a quebra de paradigmas em relação a Matemática, as implicações dessa disciplina na perspectiva de ensino aprendizagem dos estudantes e na sua abertura para o outro, consideramos essencial e urgente que ela seja apresentada na formação inicial. Atualmente a presença de estudos atrelados a Etnomatemática estão mais concentrados na pós-graduação e nos grupos de pesquisa. Apresentar a Etnomatemática na graduação se torna importante, pois muitos professores em nosso país não possuirão a oportunidade de vivenciar a experiência da pós-graduação stricto sensu.

A presença de tal disciplina na Licenciatura em Matemática parece garantir a possibilidade de aprofundamento dos pressupostos da Etnomatemática, oportunizar espaços de reflexão e diálogo e de desenvolvimento de trabalhos de campo na perspectiva etnográfica. Permite também que os graduandos possam revisitar e ressignificar algumas crenças, no que 
tange a escola, ao seu papel como professor e a sua atuação no mundo, buscando aproximações com outras áreas de conhecimento. Neste sentido, ter esse componente curricular pode ser mais favorável a uma formação crítica e criativa, do que ter a Etnomatemática inserida como conteúdo em outras disciplinas, pois nesse último caso o professor terá menos tempo para promover discussões e propor atividades de campo.

Outra observação que pode ser feita, em relação ao campo da Matemática (VILELA, 2007) é em relação a determinação dos programas de ensino, que é um dos principais objetos de disputa nesse campo. Nesse sentido, nossa pesquisa aponta que uma proposta de prática e ação na perspectiva da Etnomatemática - que dialeticamente se movimenta no interior de um sistema sociocultural, temos como agentes pesquisadores, professores e estudantes dentro de uma estrutura ainda pragmática - pode representar uma postura de resistência, visando suscitar estratégias e atitudes inovadoras em relação a Matemática eurocêntrica e excludente que ainda predomina em alguns cursos de formação de professores.

O potencial da Etnomatemática na formação inicial dos futuros professores de matemática está em nos inspirar a ter novos olhares para as práticas pedagógicas, para a escola, para nossa vivência como ser humano e para a sociedade. Aprendemos a ver o mundo a partir da perspectiva do diálogo, do respeito e da valorização das pessoas e dos construtos históricos produzidos por elas.

\section{Referências}

BARALDI, Ivete Maria. Refletindo sobre as concepções matemáticas e suas implicações para 0 ensino diante do ponto de vista dos alunos. Mimesis, Bauru, v. 20, n. 1, p. 07-18,1999.

BARTON, Bill. Dando sentido a Etnomatemática: Etnomatemática fazendo sentido. In: RIBEIRO, José Pedro Machado; DOMITE, Maria do Carmo Santos; FERREIRA, Rogério (Orgs). Etnomatemática: papel, valor e significado. 2. ed. São Paulo: Zouk, 2004, p. 39-74.

BICUDO, Maria Aparecida Viggiani. Educação Matemática (Org.) 2. ed. São Paulo: Centauro, 2005.

CARVALHO, José Sérgio Fonseca de. As noções de erro e fracasso no contexto escolar. In: AQUINO, J. G. (Org.). Erro e fracasso na escola: alternativas teóricas e práticas. São Paulo: Summus, 1997.

CHARLOT, Bernard. A noção de relação com o saber: bases de apoio teórico e fundamentos antropológicos. In: CHARLOT, Bernard (Org.). Os jovens e o saber: perspectivas mundiais. Porto Alegre: ARTMED Editora, 2001, p. 15-31.

CORTELLA, Mário Sérgio. A escola e o conhecimento: fundamentos epistemológicos e políticos. São Paulo, Cortez: Instituto Paulo Freire, 2006. 
CRAWFORD, Kate; ADLER, Jill. Teachers as Researchers in Mathematics Education. In: BISHOP, Alan et al. (Ed.) International Handbook of Mathematics Education. Dordrecht: Kluwer Academic Publishers, 1996, p. 1187-1208.

D'AMBROSIO, Ubiratan. A Transdisciplinaridade como acesso a uma história holística, In WEIL, Pierre; D'AMBROSIO, Ubiratan; CREMA, Roberto. Rumo à Nova Transdisciplinaridade: sistemas abertos de conhecimento. São Paulo: Summus, 1993, p.75-124.

D'AMBROSIO, Ubiratan. Ethnomatemathics and its place in the history and pedagogy of mathematics, In: POWEL, Arthur B.; FRANKENSTEIN, Marilyn (Eds.) Ethnomatemathics. Challenging Eurocentrism in Mathematics Education. Albany: State University of New York Press, 1997, p.13-24.

D'AMBROSIO, Ubiratan. Etnomatemática: elo entre as tradições e a modernidade. 2. ed. Belo Horizonte: Autêntica, 2005.

D'AMBROSIO, Ubiratan. O Programa Etnomatemática: uma síntese. Acta Scientiae, Canoas, v. 10, n. 1, p. 7-16, jan/jun. 2008.

D'AMBROSIO, Ubiratan; FREIRE, Paulo; DOMITE, Maria do Carmo Santos. D'Ambrosio entrevista Paulo Freire. Disponível em http://vello.sites.uol.com.br/entrevista.htm, 2009. Acesso em 12 de jul. 2020.

DOMITE, Maria do Carmo Santos. Notas sobre a formação de professores e professoras numa perspectiva da etnomatemática. In: PRIMEIRO CONGRESSO BRASILEIRO DE ETNOMATEMÁTICA-CBEm1, 2000, São Paulo. Anais ... São Paulo, 2000, p. 41-48.

DOMITE, Maria do Carmo Santos. Da compreensão sobre formação de professores e professoras numa perspectiva etnomatemática. In: KNIJNIK, G., WANDERER, F. \& OLIVEIRA, C. J. (orgs.) Etnomatemática: currículo e formação de professores. Santa Cruz do Sul: EDUNISC, 2004, p. 419 a 431.

FANTINATO, Maria Cecilia. A construção de saberes matemáticos entre jovens e adultos do Morro de São Carlos. Revista Brasileira de Educação, n. 27, p.109-124, set./dez. 2004.

FANTINATO, Maria Cecilia; FREITAS, Adriano Vargas; MARCHON, Fábio Lennon. Concepções, dinâmicas e desafios da etnomatemática. In: FANTINATO, Maria Cecilia; FREITAS, Adriano Vargas (Orgs.) Etnomatemática: concepções, dinâmicas e desafios. Jundiaí: Paco, 2018, p. 217225.

FANTINATO, Maria Cecilia, SOARES, Gisele. Américo. Etnomatemática e a Formação inicial dos Professores de Matemática: um olhar para a produção acadêmica de 2004 a 2017. 60 CONGRESSO INTERNACIONAL DE ETNOMATEMÁTICAS. 2018. Disponível em https://icem6.etnomatematica.org/index.php/icem6/icem6/paper/view/106. Acesso em 20 mar. 2020.

FERREIRA, Eduardo Sebastiani. A matemática no Pensamento de Paulo Freire. Poços de Caldas: Simpósio Paulo Freire, 1992. 
FIORENTINI, Dario. A formação matemática e didático-pedagógica nas disciplinas da Licenciatura em Matemática. Revista de Educação PUC-Campinas, Campinas, n. 18, p. 107-115, 2004.

FIORENTINI, Dario; OLIVEIRA, Ana. Teresa. Correa. Carvalho. O lugar das Matemáticas na Licenciatura em Matemática: que matemáticas e práticas formativas? Bolema, Rio Claro, v. 27, n. 47, p. 917-938, 2013.

FREIRE, Paulo. Pedagogia do Oprimido. 29. ed. [1a ed. 1970]. Rio de Janeiro: Paz e Terra, 2005.

GATTI, Bernadete. A.; NUNES, Maria Muniz. R. (Orgs.) Formação de professores para a o Ensino Fundamental: Estudos de Currículo das Licenciaturas em Pedagogia, Língua Portuguesa, Matemática e Ciências Biológicas. São Paulo: FCC/DPE, 2009. Disponível em http://www.fcc.org.br/pesquisa/publicacoes/textos_fcc/arquivos/1463/arquivoAnexado.pdf.

Acesso em 10 de fev. de 2020.

GERDES, Paulus. Etnomatemática e Educação Matemática: uma panorâmica geral. Quadrante, Lisboa, v. 5, n. 2, p. $105-138.1996$.

MONTEIRO, Alexandrina. A Etnomatemática em cenários de escolarização: alguns elementos de reflexão. In: KNIJNIK, Gelsa; WANDERER, Fernanda; OLIVEIRA, Claudio J. (Orgs.) Etnomatemática: currículo e formação de professores. Santa Cruz do Sul: EDUNISC, 2004.

MONTEIRO, Alexandrina; MENDES, Jackeline Rodrigues. A etnomatemática no encontro entre práticas e saberes: convergências, tensões e negociação de sentidos. Revista Latinoamericana de Etnomatemática, San Juan de Pasto, v. 7, n. 3, p. 55-70, 2014.

MORAES, Roque. Uma tempestade de luz: a compreensão possibilitada pela análise textual discursiva. Ciência \& Educação: Bauru, v. 9, n. 2, p. 191-210, 2003.

MOREIRA, Darlinda. A Etnomatemática e a formação de professores. Discursos. Série: Perspectiva em Educação. 2004.

MOREIRA, Darlinda. Etnomatemática e mediação de saberes matemáticos na sociedade global e multicultural. In: FANTINATO, Maria Cecilia de Castello Branco (Org). Etnomatemática: novos desafios teóricos e pedagógicos. Niterói: EdUFF, 2009, p.59-68.

MOREIRA, Darlinda. Etnomatemática em diferentes contextos sociais. In: ENCONTRO DE ETNOMATEMÁTICA DO RIO DE JANEIRO, 2014, Niterói. Anais... Niterói: UFF, 2014, p. 23-36.

PASSOS, Caroline Mendes dos. Um olhar para a etnomatemática a partir da sociologia de Pierre Bourdieu. In: QUINTO CONGRESSO BRASILEIRO DE ETNOMATEMÁTICA, 2016, Goiânia. Anais... Goiânia: UFG. 2016. p. 1-16.

RIBEIRO, José Pedro Machado. Etnomatemática e a Formação e Professores Indígenas: Um Encontro necessário em meio ao diálogo intercultural. Tese (Doutorado em Educação) Universidade de São Paulo, 2006.

SERRAZINA, Maria de Lordes M. Conhecimento matemático para ensinar: papel da planificação e da reflexão na formação de professores. Revista Eletrônica de Educação, v. 6, n. 1, maio 2012. http://dx.doi.org/10.14244/19827199355. Acesso em 15 de out. 2020. 
SHULMAN, Lee S. Those Who Understand: Knowledge Growth in Teaching. Educational Researcher. v.15, n. 2. p. 4-14, fev. 1986.

SOARES, Gisele Américo. Etnomatemática e suas marcas na Formação Inicial dos futuros professores de Matemática. 2020. 224f. Tese (Doutorado em Educação) - Universidade Federal Fluminense, Niterói.

STILLMAN, Gloria Ann; BALATTI, Josephine. Contribution of Ethnomathematics to Mainstream Mathematics Classroom Practice. In: ATWEH, Bill et al. (Eds.). Sociocultural Research on Mathematics Education. An International Perspective. Londres: Lawrence Erlbaum Associates Publishers, 2001, p. 313-328.

TARDIF, Maurice. Saberes docentes e formação profissional. Petrópolis: Vozes, 2002.

VERGANI, Teresa. Educação Etnomatemática: o que é? Lisboa: Pandora Edições, 2000.

VILELA, Denise Silva. Matemáticas nos usos e jogos de linguagem: ampliando concepções na Educação Matemática. 2007. 247f. Tese (Doutorado em Educação) - Universidade Estadual de Campinas, Campinas.

VILELA, Denise Silva. Usos e jogos de linguagem na matemática: diálogo entre filosofia e educação matemática. São Paulo: Livraria da Física, 2013. 